\title{
Editorial
}

\section{¿Malinchismo o falta de indicadores propios?}

Francisco Luis Ochoa-Jaramillo ${ }^{1 凶} \underline{\mathrm{ORCID}}$

${ }^{1}$ Médico, magíster en Epidemiología. Profesor Universidad CES. Grupos de investigación Etices y Observatorio de la Salud Pública.

Fecha correspondencia:

Recibido: junio 11 de 2021

Revisado: junio 11 de 2021.

Aceptado: junio 11 de 2021.

\section{Forma de citar:}

Ochoa-Jaramillo FL. ¿Malinchismo

o falta de indicadores propios?

Rev CES Med. 2021; 35(2): 75-76.

10.21615/cesmedicina.6294

$\underline{\text { Open access }}$

C Derecho de autor

Licencia creative commons

Ética de publicaciones

Revisión por pares

Gestión por Open Journal System

DOI: http://dx.doi.org/10.21615/

cesmedicina.6294

ISSNe 2215-9177

ISSN 0120-8705

Publica con nosotros
En nuestra anterior editorial ${ }^{(1)}$ hicimos un llamado a considerar otros sistemas de clasificación e indexación, y a que los autores, cuando escriban, lo hagan con "mirada regional" de América Latina y usando una mayor cantidad de referencias de la misma región. ¿Cuántas referencias locales y regionales se ven en un artículo de estos mismos países?, ¿cuántas están publicadas en español? Cuando buscamos las referencias para soportar un artículo ¿pensamos en los autores de aquí o siempre vamos por las referencias en inglés y extranjeras? Infortunadamente, lo que puede verse es que, en general, las referencias regionales son pocas $y$, por el contrario, pareciera que fuera pecaminoso que la producción científica local se apoyara en la producción de sus pares latinoamericanos.

Muchas personas podrán invocar el conocido mantra de "la ciencia habla inglés", pero esta afirmación también tiene sus matices, como que en la región se produce investigación de excelente calidad -que no necesariamente debe estar en dicho idioma- o que mucho de lo que se investiga regionalmente es del interés exclusivamente de la región, por lo tanto, puede ser publicada en revistas del mismo ámbito. Al respecto de lo anterior, es llamativo también que para los artículos de impacto meramente local muchas veces se presentan los datos epidemiológicos de incidencia, prevalencia o mortalidad de Estados Unidos y aun de Europa, dejando de lado la epidemiología local o propia. ¿Es esto debido a la falta de indicadores propios?, ¿a que no investigamos y publicamos nuestra propia realidad?, ¿se trata de esnobismo o de una costumbre -que pasa de generación tras generación- de respaldar nuestros resultados exclusivamente con la información de "países desarrollados"? Alentamos pues a que los investigadores locales presenten sus Investigaciones apoyados en 
lo local/regional, para mejorar los indicadores propios, pero de manera más importante, porque son el soporte para los trabajos e investigaciones de sus coterráneos.

Aquí otras razones al momento de considerar por qué publicar en revistas regionales: cada vez se hace más difícil competir con los miles de artículos de todo el mundo que son enviados a las revistas más reconocidas internacionalmente (casi todas en inglés); a ello se suma la gran cantidad de tiempo que toman para definir el status de los artículos, aparte de que muchas de ellas pertenecen a grandes monopolios y casas editoriales con evidente sentido económico que generan costos para los lectores y hasta para los mismos autores- y, finalmente, como se expresó previamente, si el alcance de los resultados de investigación es meramente local o regional, pues ese debe ser su nicho de publicación.

Quiero hacer una reflexión final al respecto de lo que ocurre con algunos expertos de la región -a quienes se invita a participar como evaluadores de los artículos y contribuir así al crecimiento de su especialidad y del corpus de conocimiento regional-, pero que, por razones diversas, no apoyan a las revistas, las investigaciones y los artículos. Nuevamente, les extendemos una amable invitación a contar con su participación, revisando y aportando con su experticia al mejoramiento de los artículos que revisan y de su disciplina. No hay difusión del conocimiento científico especializado si no hay revistas científicas. Estas no existirían si no hay autores que investiguen y publiquen sus artículos en ellas, y estos no tienen sentido y validez si no cuentan con la revisión por parte de los miembros de la respectiva comunidad científica. Unas veces somos lectores y consumidores de información, en otras somos autores y productores de esta, y en otras, velamos por su rigurosidad (que luego consumiremos). Somos iguales con distintos roles temporales. Apoyo y sentido de pertenencia con lo propio, he ahí las claves del crecimiento mutuo.

A partir de este número nuestros lectores encontrarán cambios en el diseño interior de los artículos y de la revista: tipo y tamaño de letra, espaciado y alineación de los párrafos, así como en la forma de presentación de las referencias bibliográficas y de los cuados y las figuras. Ello obecede parcialmente, a que los sistemas informáticos de gestión de las revistas solicitan algunos de estos cambios; particularmente, para su diseño en HTML, que comenzará a estar disponible en breve. Quisimos poner, además, una nueva tipografía y presentación con miras a facilitar la lectura de los artículos. Esperamos sean de su agrado.

\section{Bibliografía}

1. Ochoa-Jaramillo FL. La mirada regional. Editorial. Rev CES Med. 2021; 35(1): 1-3. 